\title{
A cohort study of patients seeking Internet gaming disorder treatment
}

\author{
DOUG HYUN HAN ${ }^{1}$, MINKYOUNG YOO ${ }^{2}$, PERRY F. RENSHAW ${ }^{3}$ and NANCY M. PETRY ${ }^{4}$ \\ ${ }^{1}$ Department of Psychiatry, Chung Ang University Hospital, Dongjak gu, Seoul Korea \\ ${ }^{2}$ Department of Economics, University of Utah, Salt Lake City, UT, USA \\ ${ }^{3}$ Department of Psychiatry, University of Utah, Salt Lake City, UT, USA \\ ${ }^{4}$ Calhoun Cardiology Center, University of Connecticut School of Medicine, Farmington, CT, USA
}

(Received: April 24, 2018; revised manuscript received: September 7, 2018; accepted: September 8, 2018)

\begin{abstract}
Background and aims: Although Internet gaming disorder (IGD) is included as a condition in the fifth edition of Diagnostic and Statistical Manual of Mental Disorders, little is known about its nature or treatment response. This study is a follow-up of 755 patients who received professional treatment for IGD over a 5-year period. Methods: The initial recommended treatment course lasted for 8 weeks, with additional care provided as needed. Treatment completion rates in the complete sample, as well as baseline predictors of treatment completion and long-term recovery among the 367 patients who completed the follow-up, are reported. Results: Nearly two thirds of patients who initiated treatment for IGD completed the 8-week psychotherapy. Of these, about two thirds who had not recovered completely by the end were offered additional care. Independent predictors of extended treatment were higher baseline scores on the Young Internet Addiction Scale, Beck Depression Inventory (BDI), and KoreanAttention Deficit Hyperactivity Disorder-Rating Scale (K-ADHD-RS). Between 1 and 5 years later, 33.5\% of the complete sample was considered as recovered from IGD. Significant predictors of recovery from IGD were older age, earlier admission to the clinic, lower baseline scores on the BDI and K-ADHD-RS, and no offer of extended treatment. Discussion and conclusions: The majority of the patients seeking treatment for IGD continued experiencing difficulties and randomized controlled trials of interventions, which are needed to be conducted to improve outcomes. Age, family, social factors, and psychological symptoms should be considered, while designing and evaluating interventions, because they impact initial and sustained response to treatment for IGD.
\end{abstract}

Keywords: Internet gaming disorder, social interaction, treatment outcomes, family, psychological symptoms

\section{INTRODUCTION}

Following a review of more than 240 articles on excessive game playing, the American Psychiatric Association's Substance Use and Related Disorders Workgroup (Petry et al., 2014) for the fifth edition of Diagnostic and Statistical Manual of Mental Disorders (DSM-5) concluded that Internet gaming disorder (IGD) is a condition for which future research might lend to a formal diagnosis (American Psychiatric Association [APA], 2013). The DSM-5 proposed a set of nine potential criteria for the identification of this condition, but it noted that greater information is needed regarding these criteria and the assessment of this condition as well as its nature, comorbidities, and treatment response (APA, 2013).

Since the publication of the DSM-5, more research on the assessment, epidemiology, and treatment of IGD has emerged. For example, Petry et al. (2014) provided suggested interpretations of the DSM-5 criteria. Although not all agreed with them (Griffiths et al., 2016; KardefeltWinther, 2014), Petry et al. (2016) reported that many of these suggestions and interpretations were considered in the initial deliberations. Furthermore, the DSM-5 guidelines and criteria appear to be appropriate for classifying persons with clinically significant problems related to gaming (Koo, Han, Park, \& Kwon, 2017; Petry et al., 2016; Sigerson, Li, Cheung, Luk, \& Cheng, 2017).

Recently, the debate that IGD would be included as a mental disorder in the International Classification of Diseases (ICD)-11 has emerged. From the clinical and public health perspective, Rumpf et al. (2018) and King et al. (2018) suggested that IGD should be classified as a mental disorder. However, Aarseth et al. (2017) identified fundamental problems in the inclusion of the IGD criteria in ICD-11. Based on substance use and gambling criteria, the premature inclusion of IGD criteria in ICD-11 may lead to false-positive cases in children and adolescents, which may have negative implications for a majority of healthy game users.

In addition to classification, understanding a disease's natural course is fundamental to evaluating its epidemiology

* Corresponding author: Doug Hyun Han, MD, PhD; Department of Psychiatry, Chung Ang University Hospital, 102 Heuk seok ro, Dongjak gu 06973, Seoul Korea; Phone: +82 26299 3132; Fax: +82 26298 1508; E-mail: hduk70@gmail.com

This is an open-access article distributed under the terms of the Creative Commons Attribution-NonCommercial 4.0 International License, which permits unrestricted use, distribution, and reproduction in any medium for non-commercial purposes, provided the original author and source are credited, a link to the CC License is provided, and changes - if any - are indicated. 
(Bhopal, 2008) and treatment (Porta, 2014). In a review of longitudinal studies on IGD, Mihara and Higuchi (2017) found that the course of IGD is variable and it may depend, in part, on age. For example, the prevalence rates of IGD in adolescents did not change substantially over time; however, they significantly decreased over periods ranging from 6 months to 5 years in adults (Mihara \& Higuchi, 2017). Similarly, a study of 3,034 Singaporean adolescents (Gentile et al., 2011) found that $84 \%$ of those with IGD at baseline still reported having symptoms in a 2-year followup survey. Other studies have focused on evaluating rates of recovery and relapse following psychological or pharmacological treatments for IGD (Forrest, King, \& Delfabbro, 2017; Han, Hwang, \& Renshaw, 2010; Han, Kim, Lee, \& Renshaw, 2012). These studies generally found that the prognosis for IGD is associated with the presence of underlying disorders, such as attention-deficit hyperactivity disorder (ADHD) and major depressive disorder (MDD), as well as with family cohesion. However, the limitations of these studies include small sample sizes, lack of consistent criteria for assessing IGD, and short follow-up periods.

This study is a naturalistic follow-up of over 750 patients who received professional treatment for IGD over a 5-year period from 2010 to 2015 . First, we report the natural rates of treatment completion for the recommended 8-week course of treatment and examine baseline differences between those who completed the initial course of treatment and those who did not. Patients who were still struggling with gaming problems were encouraged to remain in treatment after the 8-week treatment ended. Therefore, we also evaluated predictors of continued treatment beyond the initial 8 weeks. Finally, we invited all patients who completed the initial 8-week treatment to attend an in-person follow-up evaluation in 2016-2017. We report the rates of continued gaming problems at this 1- to 5-year follow-up, as well as baseline predictors of recovery from gaming problems in these patients. We hypothesized that age may impact treatment completion and long-term recovery, and comorbid conditions may adversely influence response to treatment, and that better social interactions and supportive family environments during treatment initiation would be associated with better treatment outcomes.

\section{MATERIALS AND METHODS}

\section{Study population}

The sample was drawn from 755 patients who registered at Chung Ang University Hospital's Online Game Clinic and Research Center from June 2010 to December 2015. Of the 755 original patients, 477 successfully completed the initial 8 weeks of recommended care and the remaining $278(36.8 \%)$ did not complete the 8-week treatment course. From December 1, 2016 to February 1, 2017, the hospital staff attempted to contact the initial cohort who successfully completed the initial 8 weeks of recommended care. However, 110 (23.1\% of those who completed the initial 8 weeks of treatment) patients did not respond to either phone calls or text messages and were considered lost for follow-up assessment. The other 367 patients agreed to participate in the follow-up assessment. Table 1 shows the demographic and pretreatment characteristics of the full sample, and of the completer and non-completer groups.

\section{Inclusion of patients and diagnosis of IGD}

The criteria for treatment and inclusion in this study were: (a) Internet game playing of more than $4 \mathrm{hr}$ per day or $30 \mathrm{hr}$ per week, (b) scoring $>50$ points on the Young Internet Addiction Scale (YIAS), and one or more of the following indicators of significant gaming-related distress: (a) irritable, anxious, and aggressive behaviors upon others' request to stop Internet game play; (b) economic problems or substantial family and/or social problems; (c) disruptive diurnal rhythms (difficulty waking up due to reduced sleep at night related to Internet game play); or (d) loss of job or school truancy.

\section{Study procedure}

Psychiatrists assessed patients for ADHD, MDD, mental retardation, and developmental disorders using the Structured Clinical Interview of DSM-IV-TR. All patients were asked to complete questionnaires regarding the severity of their IGD, demographic features, psychological symptoms, and social interactions. The YIAS was used to determine IGD symptom severity. Demographic information included age, sex, years of follow-up, game genre, and alcohol and tobacco use. For game genre, patients were asked to select their preference among four categories: massively multiplayer online role-playing games, real-time strategy, first-person shooter, or other. Tobacco and alcohol use were categorized as no use, occasional use (less than five cigarettes a day or drinking less than 5 days per month on an average), or regular/heavy use (more than five cigarettes per day or binge drinking on 5 or more days per month) (Kenford et al., 2005; National Institutes of Health [NIH], 2015).

Psychological factors measured at treatment initiation included intelligence quotient (IQ), ADHD, MDD, anxiety, and impulsivity. IQ was estimated using the KoreanWechsler Adult Intelligence Scale (K-WAIS), which has an internal consistency ranging from .78 to .94 (Kim, Yum, Oh, Park, \& Lee, 1992). Severity of ADHD symptoms was assessed using the Korean version of Dupaul's (1991) ADHD Rating Scale (K-ADHD-RS) with adequate reliability (an internal consistency ranging from .77 to .89 and test-retest reliability $=.85$ ) and adequate to excellent validity (excellent construct validity, adequate discriminative validity, and adequate treatment sensitivity) (Dupaul, Power, Anastopoulos, \& Reid, 1998). This version of the ADHD-RS has been validated by So, Noh, Kim, Ko, and Koh (2002). Depression and anxiety symptoms were assessed using the Beck Depression Inventory (BDI), which has an internal consistency ranging from .75 to .85 (Beck, Ward, Mendelson, Mock, \& Erbaugh, 1961) and the Beck Anxiety Inventory (BAI) with an internal consistency of .93. The Korean versions of the BDI and BAI were validated by Rhee et al. (1995) and Kwon (Kwon, 1997), respectively. Impulsivity was assessed using the Behavioral Inhibitory System/Behavioral Activation System (BIS/BAS) Scale (Carver \& White, 1994), with an internal consistency ranging from .78 to .79 . The 
Han et al.

Table 1. Demographic characteristics

\begin{tabular}{|c|c|c|c|c|}
\hline & Total (755) & Completers $(n=477)$ & Non-completers $(n=278)$ & \\
\hline Age (years)* & $22.4 \pm 6.1(11-44)$ & $21.6 \pm 5.9(11-44)$ & $22.8 \pm 5.9(12-42)$ & $t=-2.73, p<.01$ \\
\hline \multicolumn{5}{|l|}{ Age category } \\
\hline$<20(N)$ & $312(41.3 \%)$ & $212(44.4 \%)$ & $100(36.0 \%)$ & \multirow[t]{3}{*}{$\chi^{2}=6.09, p=.05$} \\
\hline $20-30(N)$ & $355(47.0 \%)$ & $216(45.3 \%)$ & $139(50.0 \%)$ & \\
\hline $30+(N)$ & $88(11.7 \%)$ & $49(10.3 \%)$ & $39(14.0 \%)$ & \\
\hline Sex (male/female) & $622 / 33(95.6 \% / 4.4 \%)$ & $454 / 23(95.2 \% / 4.8 \%)$ & $268 / 10(96.4 \% / 3.6 \%)$ & $\chi^{2}=0.63, p=.48$ \\
\hline School years (years) & $11.1 \pm 2.4(4-16)$ & $10.7 \pm 2.6(4-16)$ & $11.0 \pm 2.2(6-16)$ & $t=-1.66, p=.08$ \\
\hline \multicolumn{5}{|l|}{ Game genre } \\
\hline MMORPG & $295(39.1 \%)$ & $192(40.3 \%)$ & $103(37.1 \%)$ & \multirow[t]{4}{*}{$\chi^{2}=0.99, p=.80$} \\
\hline RTS & $309(40.9 \%)$ & $193(40.5 \%)$ & $116(41.7 \%)$ & \\
\hline FPS & $77(10.2 \%)$ & $48(10.1 \%)$ & $29(10.4 \%)$ & \\
\hline Others & $74(9.8 \%)$ & $44(9.2 \%)$ & $30(10.8 \%)$ & \\
\hline \multicolumn{5}{|l|}{ Year of initial treatment } \\
\hline 2015 & $191(25.3 \%)$ & $115(24.1 \%)$ & $76(27.3 \%)$ & \multirow[t]{6}{*}{$\chi^{2}=7.19, p=.21$} \\
\hline 2014 & $165(21.9 \%)$ & $97(20.3 \%)$ & $68(24.5 \%)$ & \\
\hline 2013 & $128(17.0 \%)$ & $78(16.4 \%)$ & $50(18.0 \%)$ & \\
\hline 2012 & $97(12.8 \%)$ & $65(13.6 \%)$ & $32(11.5 \%)$ & \\
\hline 2011 & $109(14.4 \%)$ & $74(15.5 \%)$ & $35(12.6 \%)$ & \\
\hline 2010 & $65(8.6 \%)$ & $48(10.1 \%)$ & $17(6.1 \%)$ & \\
\hline \multicolumn{5}{|l|}{ Diagnosis } \\
\hline Only IGD & $273(36.2 \%)$ & $161(33.8 \%)$ & $112(40.3 \%)$ & \multirow[t]{5}{*}{$\chi^{2}=5.43, p=.25$} \\
\hline $\mathrm{IGD}+\mathrm{ADHD}$ & $203(26.9 \%)$ & $137(28.7 \%)$ & $66(23.7 \%)$ & \\
\hline $\mathrm{IGD}+\mathrm{MDD}$ & $198(26.2 \%)$ & $127(26.6 \%)$ & $71(25.5 \%)$ & \\
\hline $\mathrm{IGD}+\mathrm{ADHD}+\mathrm{MDD}$ & $44(5.8 \%)$ & $31(6.5 \%)$ & $13(4.7 \%)$ & \\
\hline IGD + others & $37(4.9 \%)$ & $21(4.4 \%)$ & $16(5.8 \%)$ & \\
\hline \multicolumn{5}{|l|}{ Clinical scale scores } \\
\hline IQ & $98.4 \pm 14.6(50-143)$ & $98.2 \pm 14.3(50-143)$ & $98.7 \pm 15.1$ & $t=0.13, p=.89$ \\
\hline YIAS & $63.7 \pm 9.6(50-93)$ & $64.1 \pm 9.7(51-93)$ & $63.2 \pm 8.98(51-91)$ & $t=1.38, p=.17$ \\
\hline K-ADHD-RS & $20.9 \pm 12.4(0-68)$ & $21.0 \pm 13.0(0-63)$ & $20.2 \pm 13.0(0-66)$ & $t=1.26, p=.23$ \\
\hline BDI & $15.0 \pm 9.0(0-46)$ & $15.1 \pm 9.2(0-46)$ & $14.8 \pm 9.2$ & $t=0.40, p=.69$ \\
\hline BAI & $9.1 \pm 7.8(0-47)$ & $9.5 \pm 7.8(0-47)$ & $8.7 \pm 7.8$ & $t=0.52, p=.25$ \\
\hline BIS/BAS & $53.5 \pm 9.0(5-98)$ & $53.7 \pm 9.1(27-98)$ & $53.1 \pm 8.4$ & $t=0.96, p=.34$ \\
\hline \multicolumn{5}{|l|}{ Social interaction factors } \\
\hline FES* & $10.2 \pm 3.1(4-25)$ & $10.4 \pm 3.2(4-25)$ & $9.6 \pm 2.7$ & $t=3.69, p<.01$ \\
\hline SADS* & $79.7 \pm 14.2(39-130)$ & $77.8 \pm 13.4(39-130)$ & $80.6 \pm 13.7$ & $t=-2.78, p<.01$ \\
\hline \multicolumn{5}{|l|}{ Smoking } \\
\hline Heavy smoker & $70(9.3 \%)$ & $43(9.0 \%)$ & $27(9.7 \%)$ & \multirow[t]{3}{*}{$\chi^{2}=1.54, p=0.46$} \\
\hline Occasional smoker & $230(30.5 \%)$ & $153(32.1 \%)$ & $77(27.7 \%)$ & \\
\hline No use & $455(60.3 \%)$ & $281(58.9 \%)$ & $174(62.6 \%)$ & \\
\hline \multicolumn{5}{|l|}{ Alcohol use } \\
\hline Heavy alcohol use & $26(2.3 \%)$ & $19(4.0 \%)$ & $7(2.5 \%)$ & \multirow[t]{3}{*}{$\chi^{2}=4.25, p=.12$} \\
\hline Occasional alcohol use & $300(39.1 \%)$ & $200(41.9 \%)$ & $100(36.0 \%)$ & \\
\hline No use & $429(58.6 \%)$ & $258(54.1 \%)$ & $171(62.6 \%)$ & \\
\hline
\end{tabular}

Note. IGD: Internet gaming disorder; K-ADHD-RS: Korean-Attention Deficit Hyperactivity Disorder-Rating Scale; BDI: Beck Depressive Inventory; BAI: Beck Anxiety Inventory; BIS/BAS: Behavioral Inhibitory System/Behavioral Activation System Scale; FES: Family Environmental Scale; SADS: Social Avoidance and Distress Scale; MMORPG: massively multiplayer online role-playing game; RTS: real-time strategy; FPS: first-person shooter; IGD + others: IGD + autism spectrum disorder, bipolar disorder, or mental retardation; MDD: major depressive disorder; IQ: intelligent quotient.

*Statistically significant.

Korean version of the BIS/BAS Scale has been validated by Kim and Kim (2001). Using a sample of 1,515 people, Poythress et al. (2008) reported adequate reliability and validity of the BIS/BAS Scale.

The social interaction factors that are examined included family cohesion and social intimacy. Family cohesion was assessed using the Family Environment Scale (FES; Moos \& Mood, 2002), which has adequate reliability (a test-retest reliability ranging from .68 to .86 ) and adequate to excellent validity (adequate construct validity and excellent discriminative validity). Its Korean version has been validated by So et al. (2002). Higher FES scores reflect better family environments. Social intimacy was assessed using the Social Avoidance and Distress Scale (SADS; Watson \& Friend, 1969), which has adequate reliability (test-retest reliability of .68) and validity (construct and discriminative validity), with lower scores indicative of better functioning. The Korean version of the SADS has been validated by Lee and Choi (1997). 
After completing these measures during initial treatment presentation, all patients were offered treatment involving cognitive-behavioral therapy and medications for symptoms of depressive mood, poor attention, and impulse and behavior control (Kim, Han, Lee, \& Renshaw, 2012). At the end of the 8 -week course of treatment, patients who had not fully recovered from IGD were offered additional care following discussions among patients, caretakers, and psychiatrists. These additional treatments included medications for underlying diseases and supportive psychotherapy that were provided until recovery from IGD or until the patient terminated care. At the follow-up evaluation conducted in 2016-2017, occurring from 1 to 5 years after the initial presentation for treatment, a diagnosis of IGD was based on the DSM-5 diagnostic criteria (APA, 2013). The agreement between two psychiatrists' diagnoses of IGD at follow-up was $\kappa=0.89$.

\section{Model and statistical analysis}

Descriptive statistics included means and standard deviations for continuous variables, as well as counts and percentages for categorical variables. Independent $t$-tests were used to compare demographic information, including age and school years; IQ; and scores on the YIAS, K-ADHD-RS, BDI, BAI, BIS/BAS, FES, and SADS for completers and non-completers. $\chi^{2}$ tests were used to compare the groups on sex, game genre, smoking and alcohol use, comorbid psychiatric diagnoses, and year of initial treatment. An $\alpha<.05$ level was considered statistically significant.

Next, a logistic regression analysis was conducted to identify the predictors of the completion of the 8-week treatment in the entire sample. Independent variables included age; school year; gender; game genre; year of treatment; YIAS, BDI, BAI, BIS/BAS, SADS, FES, K-ADHD-RS, and IQ scores; and smoking and alcohol use. The dependent variable, completion of the 8-week treatment, was operationalized as a binary code (1: completion/0: non-completion). In addition, we used a logistic regression analysis to identify the predictors of receiving more than 8 weeks of treatment among the 477 completers. The independent variables were identical to those outlined above. Finally, we used a third multivariate logistic regression analysis to identify the predictors of recovery from IGD among the 367 completers who participated in the follow-up evaluation. In this analysis, the independent variables included the same variables as those in the initial regression, in addition to whether the patient received more than the initial 8 weeks of treatment. The dependent variable, recovery from IGD, was operationalized based on clinical impressions using the DSM-5's diagnostic criteria for IGD (APA, 2013). All analyses were performed using Statistical Analysis System, version 9 (SAS ${ }^{\circledR}$, SAS Institute Inc., NC, USA).

\section{Ethics}

The study procedures were performed in accordance with the Declaration of Helsinki. The institutional review board of Chung-Ang University Hospital approved the research protocol for this study. All participants were informed about the procedures of this study and provided written informed consent. The written informed consent was provided by patients aged 18 years or above. For patients aged below 18 years, informed assent was obtained from their parents who provided written informed consent.

\section{RESULTS}

\section{Comparison of demographic characteristics between 8-week treatment completers and non-completers}

In the entire sample, $63.1 \%$ of the patients completed 8 weeks of treatment. Univariate analyses revealed that completers were significantly younger and had better FES and social avoidance scores as compared to the non-completers (Table 1).

The logistic regression analyses also evaluated the unique predictive impact of these variables (data not shown, but they are available from the authors). The overall model was significant in predicting failure to complete 8 weeks of treatment, $\chi^{2}(19)=54.84, p<.001$. Similar to the results derived from the univariate analyses, significant predictors of the completion of 8 weeks of treatment were age, $\beta=$ $-0.05(S E=0.01)$, Wald $=-3.25, p<.01$, odds ratio $=$ $0.95[95 \%$ confidence interval $(\mathrm{CI})=0.93-0.98]$; lower social avoidance, $\beta=-0.02(S E=0.01)$, Wald $=-2.66$, $p=.01$, odds ratio $=0.99(95 \% \mathrm{CI}=0.97-1.00)$; and better family environment, $\beta=-0.11(S E=0.03)$, Wald $=3.61$, $p<.01$, odds ratio $=0.90(95 \% \mathrm{CI}=1.05-1.18)$. No other variables significantly predicted completion of treatment.

\section{Logistic regression predicting extended treatment $(n=477)$}

Independent predictors of extended treatment were higher baseline scores on the YIAS, BDI, and K-ADHD-RS (Table 2). Among the completers $(n=477), 298(62.5 \%)$ were offered and received additional treatment, with an average of $5.1 \pm 3.6$ additional months of treatment (ranging from 1 to 27 months).

\section{Logistic regression predicting recovery from IGD at follow-up $(n=367)$}

Table 3 shows the results of the logistical regression analysis predicting continued treatment beyond the initial 8 weeks. The overall model was significant, $\chi^{2}(19)=57.59, p<.001$. The independent predictors of extended treatment were higher baselines scores on the YIAS, BDI, and K-ADHD-RS (Table 2). Among those who completed at least the initial 8 weeks of treatment and who participated in the follow-up evaluation in 2016-2017, 253 (68.9\%) patients were classified as having recovered from IGD. The key predictors of long-term recovery from IGD were older age, earlier admission to the clinic (longer length of followup), lower baseline BDI and K-ADHD-RS scores, and having received just 8 weeks of treatment.

\section{DISCUSSION}

IGD patients who completed the 8-week treatment (completers) were younger, and had better family environments 
Han et al.

Table 2. Logistic regression predicting extended treatment $(n=477)$

\begin{tabular}{|c|c|c|c|c|c|c|c|}
\hline & $\beta$ & $S E$ & Wald & $p$ & OR & \multicolumn{2}{|c|}{$95 \% \mathrm{CI}$} \\
\hline Age & -0.03 & 0.02 & -1.57 & .12 & 0.97 & 0.93 & 1.01 \\
\hline Years of schooling & 0.15 & 0.09 & 3.17 & .09 & 1.16 & 0.99 & 1.39 \\
\hline \multicolumn{8}{|l|}{ Gender $^{\mathrm{a}}$} \\
\hline Female & \multicolumn{7}{|c|}{ Reference } \\
\hline Male & 0.16 & 0.43 & 0.37 & .71 & 1.17 & 0.51 & 2.70 \\
\hline \multicolumn{8}{|l|}{ Game genre $^{\mathrm{a}}$} \\
\hline MMORPG & \multicolumn{7}{|c|}{ Reference } \\
\hline RTS & 0.29 & 0.23 & 1.27 & .21 & 1.34 & 0.85 & 2.10 \\
\hline FPS & 0.55 & 0.38 & 1.45 & .15 & 1.73 & 0.82 & 3.65 \\
\hline Others & -0.19 & 0.37 & -0.52 & .61 & 0.82 & 0.39 & 1.72 \\
\hline Year of treatment ${ }^{\mathrm{a}}$ & -0.06 & 0.06 & -0.88 & .38 & 0.95 & 0.83 & 1.07 \\
\hline \multicolumn{8}{|l|}{ Clinical scale } \\
\hline IQ & -0.01 & 0.01 & -1.23 & .22 & 0.99 & 0.97 & 1.01 \\
\hline YIAS* & 0.04 & 0.01 & 2.92 & .01 & 1.04 & 1.01 & 1.08 \\
\hline BDI* & 0.03 & 0.01 & 2.19 & .03 & 1.03 & 1.00 & 1.06 \\
\hline BAI & 0.01 & 0.01 & 0.67 & .51 & 1.01 & 0.98 & 1.04 \\
\hline BIS/BAS & 0.01 & 0.01 & 0.67 & .51 & 1.02 & 0.95 & 1.09 \\
\hline K-ADHD-RS* & 0.03 & 0.01 & 3.05 & $<.01$ & 1.03 & 1.01 & 1.05 \\
\hline \multicolumn{8}{|l|}{ Social interaction factors } \\
\hline SADS & 0.01 & 0.01 & 1.09 & .28 & 1.01 & 0.99 & 1.03 \\
\hline FES & 0.02 & 0.04 & 0.46 & .65 & 1.03 & 0.95 & 1.09 \\
\hline \multicolumn{8}{|l|}{ Smoking status ${ }^{\mathrm{a}}$} \\
\hline Heavy smoker & \multicolumn{7}{|c|}{ Reference } \\
\hline Occasional smoker & -0.23 & 0.37 & -0.61 & .54 & 0.80 & 0.38 & 1.66 \\
\hline No use & -0.07 & 0.45 & -0.15 & .88 & 0.94 & 0.39 & 2.25 \\
\hline \multicolumn{8}{|l|}{ Alcohol use ${ }^{a}$} \\
\hline Heavy alcohol use & & & & erence & & & \\
\hline Occasional alcohol use & -0.59 & 0.52 & -1.14 & .26 & 0.55 & 0.20 & 1.53 \\
\hline No use & -0.89 & 0.59 & -1.51 & .13 & 0.41 & 0.13 & 1.31 \\
\hline
\end{tabular}

Note. MMORPG: massively multiplayer online role-playing game; RTS: real-time strategy; FPS: first-person shooter; K-ADHD-RS: KoreanAttention Deficit Hyperactivity Disorder-Rating Scale; BDI: Beck Depressive Inventory; BAI: Beck Anxiety Inventory; BIS/BAS: Behavioral Inhibitory System/Behavioral Activation System Scale; FES: Family Environment Scale; SADS: Social Avoidance and Distress Scale; YIAS: Young Internet Addiction Scale; CI: confidence interval; OR: odds ratio; IQ: intelligent quotient; SE: standard error. ${ }^{\mathrm{a} C a t e g o r i c a l ~ v a r i a b l e s . ~}$

*Statistically significant results at $\alpha=.05$; dependent variable (1/0): more than 8 weeks of treatment/just 8 weeks of treatment.

and lower social avoidance than their counterparts did. Most likely, younger age was associated with greater initial treatment completion, because families were more involved in encouraging treatment attendance. The importance of family environment has been emphasized in other studies on IGD (Han et al., 2012; Lam, 2014; Yen et al., 2012), and poor cohesion and functioning between a parent and child are risk factors for gaming and Internet problems in general (Hyun et al., 2015; Yen et al., 2012). Numerous studies have demonstrated associations between social anxiety symptoms and IGD (Ioannidis et al., 2018; Sigerson et al., 2017), and data from this study suggest that those with greater social avoidance are less likely to complete the treatment course for IGD.

Not surprisingly, more severe gaming problems, as assessed by the YIAS during treatment initiation, were associated with greater likelihood of being offered extended treatment for IGD. In addition, greater depression and ADHD symptoms at baseline predicted the need for more extended care. Both depression and ADHD may lead to and/ or stem from gaming problems (Bae, Han, Kim, Shi, \& Renshaw, 2016; Han et al., 2009, 2010; Han, Lee, Shi, \& Renshaw, 2014), and greater symptom severity during initiating treatment appears to be related to the need for more extensive care.

The key predictors of recovery from IGD at the long-term follow-up were having received only 8 weeks of treatment, earlier admission to the clinic (i.e., more years of follow-up), older age, and lower baseline BDI and ADHD scores. As noted earlier, those who were not offered extended treatment had lower baseline scores for gaming problem severity. Surprisingly, those who were considered as "recovered" at the end of the 8-week-treatment program could not be a predictor of extended recovery from IGD. Earlier admission was associated with better long-term outcomes, which may reflect better treatment provided in the earlier, relative to later, years, and/or that the patients "outgrew" their gaming problems as they aged. Older age at treatment initiation, which was related to poorer initial treatment completion, was associated with better long-term recovery. This may also be influenced by the age-related differences in follow-up completion in this sample, in which non-completers were more likely to be older at treatment initiation. Older completers may have been more likely to do well in treatment than their non-completer counterparts were. It is also possible that older 
Cohort study of Internet gaming disorder

Table 3. Logistic regression predicting recovery from IGD at the follow-up $(n=367)$

\begin{tabular}{|c|c|c|c|c|c|c|c|}
\hline & $\beta$ & $S E$ & Wald & $p$ & OR & \multicolumn{2}{|c|}{$95 \% \mathrm{CI}$} \\
\hline Age* & 0.11 & 0.02 & 4.95 & $<.01$ & 1.12 & 1.07 & 1.17 \\
\hline Years of schooling (year) & 0.09 & 0.07 & 1.92 & .17 & 0.96 & 0.91 & 1.25 \\
\hline \multicolumn{8}{|l|}{ Gender $^{\mathrm{a}}$} \\
\hline Female & & & & Reference & & & \\
\hline Male & 0.26 & 0.65 & 0.39 & .69 & 1.29 & 0.36 & 4.66 \\
\hline \multicolumn{8}{|l|}{ Game genre $^{\mathrm{a}}$} \\
\hline MMORPG & & & & Reference & & & \\
\hline RTS & -0.22 & 0.26 & -0.85 & .40 & 0.80 & 0.48 & 1.33 \\
\hline FPS & -0.07 & 0.41 & -0.17 & .86 & 0.93 & 0.41 & 2.09 \\
\hline Others & 0.08 & 0.46 & 0.17 & .87 & 1.08 & 0.44 & 2.65 \\
\hline Year of treatment* & -0.34 & 0.08 & -3.96 & $<.01$ & 0.71 & 0.60 & 0.84 \\
\hline \multicolumn{8}{|l|}{ Clinical scales } \\
\hline IQ & 0.00 & 0.01 & -0.27 & .79 & 1.00 & 0.98 & 1.01 \\
\hline YIAS & -0.01 & 0.02 & 0.11 & .14 & 0.96 & 0.91 & 1.01 \\
\hline BDI* & -0.05 & 0.02 & -3.02 & $<.01$ & 0.95 & 0.92 & 0.98 \\
\hline BAI & -0.02 & 0.02 & -1.56 & .12 & 0.98 & 0.95 & 1.01 \\
\hline BIS/BAS & -0.02 & 0.01 & -1.47 & .14 & 0.98 & 0.95 & 1.01 \\
\hline K-ADHD-RS* & -0.03 & 0.01 & -3.53 & $<.01$ & 0.97 & 0.95 & 0.98 \\
\hline \multicolumn{8}{|l|}{ Social interaction factors } \\
\hline SADS & -0.01 & 0.01 & -0.97 & .33 & 0.99 & 0.98 & 1.01 \\
\hline FES & -0.05 & 0.04 & -1.23 & .22 & 0.95 & 0.89 & 1.03 \\
\hline \multicolumn{8}{|l|}{ Smoking status ${ }^{\mathrm{a}}$} \\
\hline Heavy smoker & & & & Reference & & & \\
\hline Occasional smoker & 0.13 & 0.50 & 0.26 & .79 & 1.14 & 0.43 & 3.06 \\
\hline No use & -0.28 & 0.64 & -0.43 & .67 & 0.76 & 0.22 & 2.66 \\
\hline \multicolumn{8}{|l|}{ Alcohol use $\mathrm{a}^{\mathrm{a}}$} \\
\hline Heavy alcohol use & & & & Reference & & & \\
\hline Occasional alcohol use & 0.01 & 0.76 & 0.02 & .99 & 1.01 & 0.23 & 4.46 \\
\hline No use & 0.68 & 0.84 & 0.81 & .42 & 1.97 & 0.38 & 10.22 \\
\hline \multicolumn{8}{|l|}{ Extended treatment ${ }^{\mathrm{a}}$} \\
\hline Beyond 8 weeks & & & & Reference & & & \\
\hline Just 8 weeks* & 1.57 & 0.35 & 17.66 & $<.01$ & 4.29 & 2.49 & 9.42 \\
\hline
\end{tabular}

Note. MMORPG: massively multiplayer online role-playing game; RTS: real-time strategy; FPS: first-person shooter; K-ADHD-RS: KoreanAttention Deficit Hyperactivity Disorder-Rating Scale; BDI: Beck Depressive Inventory; BAI: Beck Anxiety Inventory; BIS/BAS: Behavioral Inhibitory System/Behavioral Activation System Scale; FES: Family Environment Scale; SADS: Social Avoidance and Distress Scale; YIAS: Young Internet Addiction Scale; CI: confidence interval; OR: odds ratio; IQ: intelligent quotient; $S E$ : standard error. ${ }^{\mathrm{a} C}$ Categorical variables.

*Statistically significant results at $\alpha=.05$; dependent variable (1/0): recovery from IGD/non-recovery from IGD.

non-completers may have dropped out of care, because they successfully stopped gaming. Future studies should evaluate long-term outcomes regardless of treatment completion.

Baseline depression and ADHD symptoms, which were associated with the need for more extended treatment, were also inversely related to long-term recovery. These psychological symptoms are associated with the development of IGD (Carli et al., 2013). Thus, this study extends the existing knowledge and acknowledges the need for more extended treatment as well as better long-term outcomes. We have previously demonstrated that treatment for IGD reduces ADHD (Han et al., 2009) and depression (Han et al., 2010) symptoms, but greater symptom severity during initiation also results in greater need for extended treatment and poorer rates of recovery from IGD. In this study, neither impulsivity nor general anxiety symptoms predicted treatment completion or outcomes.

Similarly, in this study, neither IQ, preferred form of game, nor substance use was associated with outcomes.
All of these variables have been related to the development of gaming problems (Lee, Han, Kim, \& Renshaw, 2013; Morioka et al., 2017; Park et al., 2011), but this is the first known study to examine their impact on outcomes of treatment for gaming problems. At least in this sample, they did not appear to impact the length of recommended treatment for IGD or long-term treatment outcomes.

There were several limitations to this study. First, we only attempted to follow-up patients who completed the initial 8 weeks of treatment, and about $25 \%$ of the initial treatment completers did not participate in the follow-up. Thus, our results may be influenced by factors that impacted dropout from treatment, as well as failure or refusal to complete the follow-up. The IGD criteria, as defined in the DSM-5, were not available when the initial cohort began treatment in 2010 , but it is likely all participants initially had clinically significant problems with gaming. Typically, only persons with relatively severe symptoms seek treatment. This study was a naturalistic follow-up of patients who 
began treatment over a 5-year period. Therefore, naturally occurring changes in treatment, gaming, and the society may also have impacted the results. The duration of the follow-up period also differed substantially across cohorts, ranging from 1 to 5 years after treatment initiation. Moreover, this study did not evaluate the efficacy or even the consistency of the treatment applied. Therefore, the specificity of these outcomes may or may not relate to the interventions delivered. In future analyses, we will include scheduled follow-ups of clinical and psychological data.

\section{CONCLUSIONS}

Nearly two thirds of patients who initiated treatment for IGD completed an 8-week course of psychotherapy. Of these, about two thirds were not considered fully recovered and were offered additional care. Between 1 and 5 years later, about one third of the initial sample (253 of 755 , $33.5 \%$ ), or one half of the completers ( 253 of $477,49.3 \%$ ) were considered to have recovered from IGD. These data suggest that treatment for IGD is effective, but randomized controlled trials examining the effects of specific interventions are lacking. In designing and evaluating interventions, age, and family and social factors should be considered, since younger patients and those with greater family and social support exhibited improved initial engagement and response to treatment. On the other hand, older age and fewer depression and ADHD symptoms may be positively associated with long-term recovery from IGD.

Funding sources: This work was supported by Korean Game Culture Foundation (KOCCA17-80).

Authors' contribution: DHH and PFR designed the study and wrote the protocol. MY conducted the statistical analysis. NMP wrote the manuscript and all authors contributed to and have approved the final version of the manuscript.

Conflict of interest: The authors report no conflict of interest.

\section{REFERENCES}

Aarseth, E., Bean, A. M., Boonen, H., Carras, M. C., Coulson, M., Das, D., Deleuze, J., Dunkels, E., Edman, J., Ferguson, C. J., Haagsma, M. C., Helmersson Bergmark, K., Hussain, Z., Jansz, J., Kardefelt-Winther, D., Kutner, L., Markey, P., Nielsen, R. K. L., Prause, N., Przybylski, A., Quandt, T., Schimmenti, A., Starcevic, V., Stutman, G., Van Looy, J., \& Van Rooij, A. J. (2017). Scholars' open debate paper on the World Health Organization ICD-11 Gaming Disorder proposal. Journal of Behavioral Addictions, 6(3), 267-270. doi:10.1556/2006.5.2016.088

American Psychiatric Association [APA]. (2013). Diagnostic and statistical manual of mental disorders (DSM-5) (5th ed.). Arlington, VA: American Psychiatric Association.
Bae, S., Han, D. H., Kim, S. M., Shi, X., \& Renshaw, P. F. (2016). Neurochemical correlates of Internet game play in adolescents with attention deficit hyperactivity disorder: A proton magnetic resonance spectroscopy (MRS) study. Psychiatry Research, 254, 10-17. doi:10.1016/j.pscychresns.2016.05.006

Beck, A. T., Ward, C. H., Mendelson, M., Mock, J., \& Erbaugh, J. (1961). An inventory for measuring depression. Archives of General Psychiatry, 4(6), 561-571. doi:10.1001/archpsyc. 1961.01710120031004

Bhopal, R. S. (2008). Interrelated concepts in the epidemiology of disease: Natural history, spectrum, iceberg, population patterns, and screening. Oxford, UK: Oxford University Press.

Carli, V., Durkee, T., Wasserman, D., Hadlaczky, G., Despalins, R., Kramarz, E., Wasserman, C., Sarchiapone, M., Hoven, C. W., Brunner, R., \& Kaess, M. (2013). The association between pathological Internet use and comorbid psychopathology: A systematic review. Psychopathology, 46(1), 1-13. doi:10.1159/ 000337971

Carver, C. S., \& White, T. L. (1994). Behavioral inhibition, behavioral activation, and affective responses to impending reward and punishment: The BIS/BAS Scales. Journal of Personality and Social Psychology, 67(2), 319-333. doi:10.1037/0022-3514.67.2.319

Dupaul, G. J. (1991). Parent and teacher ratings of ADHD symptoms - Psychometries in a community-based sample. Journal of Clinical Child and Adolescent Psychology, 20(3), 245-253. doi:10.1207/s15374424jccp2003_3

Dupaul, G. J., Power, T. J., Anastopoulos, A. D., \& Reid, R. (1998). ADHD Rating Scale-IV. New York, NY: Guilford Publications.

Forrest, C. J., King, D. L., \& Delfabbro, P. H. (2017). Maladaptive cognitions predict changes in problematic gaming in highlyengaged adults: A 12-month longitudinal study. Addictive Behaviors, 65, 125-130. doi:10.1016/j.addbeh.2016.10.013

Gentile, D. A., Choo, H., Liau, A., Sim, T., Li, D., Fung, D., \& Khoo, A. (2011). Pathological video game use among youths: A two-year longitudinal study. Pediatrics, 127(2), e319-e329. doi:10.1542/peds.2010-1353

Griffiths, M. D., van Rooij, A. J., Kardefelt-Winther, D., Starcevic, V., Kiraly, O., Pallesen, S., Müller, K., Dreier, M., Carras, M., Prause, N., King, D. L., Aboujaoude, E., Kuss, D. J., Pontes, H. M., Lopez Fernandez, O., Nagygyorgy, K., Achab, S., Billieux, J., Quandt, T., Carbonell, X., Ferguson, C. J., Hoff, R. A., Derevensky, J., Haagsma, M. C., Delfabbro, P., Coulson, M., Hussain, Z., \& Demetrovics, Z. (2016). Working towards an international consensus on criteria for assessing Internet gaming disorder: A critical commentary on Petry et al. (2014). Addiction, 111(1), 167-175. doi:10.1111/add.13057

Han, D. H., Hwang, J. W., \& Renshaw, P. F. (2010). Bupropion sustained release treatment decreases craving for video games and cue-induced brain activity in patients with Internet video game addiction. Experimental and Clinical Psychopharmacology, 18(4), 297-304. doi:10.1037/a0020023

Han, D. H., Kim, S. M., Lee, Y. S., \& Renshaw, P. F. (2012). The effect of family therapy on the changes in the severity of online game play and brain activity in adolescents with online game addiction. Psychiatry Research, 202(2), 126-131. doi:10.1016/ j.pscychresns.2012.02.011

Han, D. H., Lee, Y. S., Na, C., Ahn, J. Y., Chung, U. S., Daniels, M. A., Haws, C. A., \& Renshaw, P. F. (2009). The effect of methylphenidate on Internet video game play in children with 
attention-deficit/hyperactivity disorder. Comprehensive Psychiatry, 50(3), 251-256. doi:10.1016/j.comppsych.2008.08.011

Han, D. H., Lee, Y. S., Shi, X., \& Renshaw, P. F. (2014). Proton magnetic resonance spectroscopy (MRS) in online game addiction. Journal of Psychiatric Research, 58, 63-68. doi:10.1016/j.jpsychires.2014.07.007

Hyun, K. J., Han, D. H., Lee, Y. S., Kang, K. D., Yoo, S. K., Chung, U., \& Renshaw, P. (2015). Risk factors associated with online game addiction: A hierarchical model. Computers in Human Behavior, 48, 706-713. doi:10.1016/j.chb.2015.02.008

Ioannidis, K., Treder, M. S., Chamberlain, S. R., Kiraly, F., Redden, S. A., Stein, D. J., Lochner, C., \& Grant, J. E. (2018). Problematic Internet use as an age-related multifaceted problem: Evidence from a two-site survey. Addictive Behaviors, 81, 157-166. doi:10.1016/j.addbeh.2018.02.017

Kardefelt-Winther, D. (2014). A conceptual and methodological critique of Internet addiction research: Towards a model of compensatory Internet use. Computers in Human Behavior, 31, 351-354. doi:10.1016/j.chb.2013.10.059

Kenford, S. L., Wetter, D. W., Welsch, S. K., Smith, S. S., Fiore, M. C., \& Baker, T. B. (2005). Progression of college-age cigarette samplers: What influences outcome. Addictive Behaviors, 30(2), 285-294. doi:10.1016/j.addbeh.2004.05.017

Kim, J. K., Yum, T. H., Oh, K. J., Park, Y. S., \& Lee, Y. H. (1992). Item analysis of K-WAIS revised version. The Korean Journal of Clinical Psychology, 11, 1-10.

Kim, K. H., \& Kim, W. S. (2001). Korean-BAS/BIS Scale. The Korean Journal of Health Psychology, 6, 19-37.

Kim, S. M., Han, D. H., Lee, Y. S., \& Renshaw, P. F. (2012). Combined cognitive behavioral therapy and bupropion for the treatment of problematic online game play in adolescents with major depressive disorder. Computers in Human Behaviors, 28(5), 1954-1959. doi:10.1016/j.chb.2012.05.015

King, D. L., Delfabbro, P. H., Potenza, M. N., Demetrovics, Z., Billieux, J., \& Brand, M. (2018). Internet gaming disorder should qualify as a mental disorder. Australian and New Zealand Journal of Psychiatry, 52(7), 615-617. doi:10.1177/0004867418771189

Koo, H. J., Han, D. H., Park, S. Y., \& Kwon, J. H. (2017). The structured clinical interview for DSM-5 Internet gaming disorder: Development and validation for diagnosing IGD in adolescents. Psychiatry Investigation, 14(1), 21-29. doi:10.4306/ pi.2017.14.1.21

Kwon, S. M. (1997). The assessment of psychopathology in patient with anxiety disorder. The Korean Journal of Psychopathology, 6, 37-51.

Lam, L. T. (2014). Risk factors of Internet addiction and the health effect of Internet addiction on adolescents: A systematic review of longitudinal and prospective studies. Current Psychiatry Reports, 16(11), 508. doi:10.1007/s11920-014-0508-2

Lee, J. Y., \& Choi, J. H. (1997). The effects of the cognitivebehavioral and exposure therapy for social phobia. Korean Journal of Counseling and Psychotherapy, 9, 35-56.

Lee, Y. S., Han, D. H., Kim, S. M., \& Renshaw, P. F. (2013). Substance abuse precedes Internet addiction. Addictive Behaviors, 38(4), 2022-2025. doi:10.1016/j.addbeh.2012. 12.024

Mihara, S., \& Higuchi, S. (2017). Cross-sectional and longitudinal epidemiological studies of Internet gaming disorder: A systematic review of the literature. Psychiatry and Clinical Neurosciences, 71(7), 425-444. doi:10.1111/pcn.12532
Moos, R., \& Mood, B. (2002). Family environment scale manual. Palo Alto, CA: Mind Garden.

Morioka, H., Itani, O., Osaki, Y., Higuchi, S., Jike, M., Kaneita, Y., Kanda, H., Nakagome, S., \& Ohida, T. (2017). The association between alcohol use and problematic Internet use: A large-scale nationwide cross-sectional study of adolescents in Japan. Journal of Epidemiology, 27(3), 107-111. doi:10.1016/ j.je.2016.10.004

National Institutes of Health [NIH]. (2015). Dietary guidelines for Americans 2015-2020. Vermont: U.S. Department of Health and Human Services/U.S. Department of Agriculture.

Park, M. H., Park, E. J., Choi, J., Chai, S., Lee, J. H., Lee, C., \& Kim, D. J. (2011). Preliminary study of Internet addiction and cognitive function in adolescents based on IQ tests. Psychiatry Research, 190(2-3), 275-281. doi:10.1016/j.psychres.2011.08.006

Petry, N. M., Rehbein, F., Gentile, D. A., Lemmens, J. S., Rumpf, H. J., Mossle, T., Bischof, G., Tao, R., Fung, D. S., Borges, G., Auriacombe, M., GonzálezIbáñez, A., Tam, P., \& O'Brien, C. P. (2014). Moving Internet gaming disorder forward: A reply. Addiction, 109(9), 1412-1413. doi:10.1111/ add. 12653

Petry, N. M., Rehbein, F., Gentile, D. A., Lemmens, J. S., Rumpf, H. J., Mossle, T., Bischof, G., Tao, R., Fung, D. S., Borges, G., Auriacombe, M., González-Ibáñez, A., Tam, P., \& O'Brien, C. P. (2016). Griffiths et al.'s comments on the international consensus statement of Internet gaming disorder: Furthering consensus or hindering progress? Addiction, 111(1), 175-178. doi:10.1111/ add. 13189

Porta, M. (2014). Natural history of disease. Oxford, UK: Oxford University Press.

Poythress, N. G., Skeem, J. L., Weir, J., Lilienfeld, S. O., Douglas, K. S., Edens, J. F., \& Kennealy, P. J. (2008). Psychometric properties of Carver and White's (1994) BIS/BAS Scales in a large sample of offenders. Personality and Individual Differences, 45(8), 732-737. doi:10.1016/j. paid.2008.07.021

Rhee, M. K., Lee, Y. H., Park, S. H., Sohn, C. H., Hong, S. K., Son, C. H., Jeong, Y. J., Chang, P., \& Yoon, A. R. (1995). A standardization study of Beck Depression Inventory 1-Korean version (K-BDI): Reliability and factor analysis. Korean Journal of Psychopathology, 4, 77-95.

Rumpf, H. J., Achab, S., Billieux, J., Bowden-Jones, H., Carragher, N., Demetrovics, Z., Higuchi, S., King, D. L., Mann, K., Potenza, M., Saunders, J. B., Abbott, M., Ambekar, A., Aricak, O. T., Assanangkornchai, S., Bahar, N., Borges, G., Brand, M., Chan, E. M., Chung, T., Derevensky, J., Kashef, A. E., Farrell, M., Fineberg, N. A., Gandin, C., Gentile, D. A., Griffiths, M. D., Goudriaan, A. E., Grall-Bronnec, M., Hao, W., Hodgins, D. C., Ip, P., Király, O., Lee, H. K., Kuss, D., Lemmens, J. S., Long, J., LopezFernandez, O., Mihara, S., Petry, N. M., Pontes, H. M., Rahimi-Movaghar, A., Rehbein, F., Rehm, J., Scafato, E., Sharma, M., Spritzer, D., Stein, D. J., Tam, P., Weinstein, A., Wittchen, H. U., Wölfling, K., Zullino, D., \& Poznyak, V. (2018). Including gaming disorder in the ICD-11: The need to do so from a clinical and public health perspective. Journal of Behavioral Addictions, 7(3), 556-561. doi:10.1556/2006.7. 2018.59 
Sigerson, L., Li, A. Y., Cheung, M. W., Luk, J. W., \& Cheng, C. (2017). Psychometric properties of the Chinese Internet Gaming Disorder Scale. Addictive Behavior, 74, 20-26. doi:10.1016/j.addbeh.2017.05.031

So, Y. K., Noh, J. S., Kim, Y. S., Ko, S. G., \& Koh, Y. J. (2002). The reliability and validity of Korean Parent and Teacher ADHD Rating Scale. Journal of Korean Neuropsychiatric Association, 41, 283-289.
Watson, D., \& Friend, R. (1969). Measurement of socialevaluative anxiety. Journal of Consulting and Clinical Psychology, 33(4), 448-457. doi:10.1037/h0027806

Yen, J. Y., Yen, C. F., Chen, C. S., Wang, P. W., Chang, Y. H., \& Ko, C. H. (2012). Social anxiety in online and real-life interaction and their associated factors. Cyberpsychology, Behavior, and Social Networking, 15(1), 7-12. doi:10.1089/ cyber.2011.0015 